\title{
A Study to Assess The Efficacy of Balloon Angioplasty of The femoropopliteal Arteries in The Relief of Critical Limb Ischemia (CLI)
}

\author{
Ehab M. Abdo*, Hatem A. Mgahid,Abdel Aziz Abo Elella, \\ Vascular Surgery Unit, Al-Zhraa University Hospital, Faculty of Medicine, Al-Azhar \\ University, Cairo.
}

\begin{abstract}
:
Purpose: The aim of the study was to evaluate the results of percutaneous transluminal angioplasty (PTA) of femoropopliteal arteries in patients with critical lower limb ischemia;

Materials and methods: From June 2006 till May 2008, 40 patients underwent 40 PTA procedures, 18 were of the superficial femoral artery (SFA), 7 of the popliteal artery, 9 of both arteries and 6 of the common femoral artery (CFA). Twenty-nine procedures were performed for treatment of stenoses and 11 for occlusion. The patients were monitored clinically with non-invasive hemodynamic studies.
\end{abstract}

Results: The technical success rate was $97.5 \%$. Overall primary patency rates at 24 months were $67.5 \%$. Primary patency rates in limbs with occlusion were $45.5 \%$ compared with 75.9 in limbs with stenoses. Two major amputations were performed. The overall survival rate was $95 \%$.

Conclusion: The 2 years results of femoropopliteal PTA performed for treatment of CLI seemed to be near the results of infrainguinal bypass grafting reported in literature. Because PTA does not preclude the performance of future surgery and associated with low morbidity and mortality rates, it should be a first choice treatment for patients with CLI for selected lesions.

\section{Introduction:}

Transatlantic Inter-Society Consensus (TASC) for the management of peripheral arterial disease (PAD) defined CLI for all patients with chronic ischemic rest pain, ulcers or gangrene attributable to objectively proven arterial occlusive disease (TASC II, 2007a). CLI is a common problem. Its incidence in UK is estimated to be between 50-100 cases per 100000 populations per year. Sixteen percent undergo primary major amputation. CLI was previously considered as a primary indication for bypass surgery and percutaneous transluminal balloon angioplasty was only considered if the patient was at high risk for surgery or if autogenous bypass material was not available (Nasr et al.,2002)

\section{Aim of the Work :}

The aim of this study is to evaluate the efficacy of percutanous transluminal balloon angioplasty of the femoropopliteal arterial lesions in patients who present with CLI.

Materials and methods :

From June 2006 till May 2008, 40 patients with CLI who underwent 40 femoropopliteal PTA procedures in Al-Zhraa University Hospital were evaluated in this study. All patients included in this study were subjected to full medical history, physical examination, basic haematologic and biochemical tests. Patients who presented with chronic rest pain, ulcers or gangrene were subjected to pressure measurements to prove that they are attributable to arterial occlusive disease ( ankle and toe pressure measurements and transcutaneous oxygen measurements (TCPO2)

Arterial occlusive disease is suggested if either ankle pressure $<50-70 \mathrm{mmHg}$ or reduced toe pressure $<30-50 \mathrm{mmHg}$ or reduced TCPO $2<30-50 \mathrm{mmHg}$.

The mean ankle/brachial pressure index (ABPI) was 0.36 before PTA. A complete arteriogram from the level of the renal arteries to the level of the pedal arch was performed to correctly plan treatment. Patients underwent crural artery PTA simultaneously with femoropopliteal PTA are excluded. PTA was performed in the angiography suite (using Philips multidiagnost 3 DSI with the technology of road mapping) under local anaesthesia . Low profile balloon catheters (A-Trac, Fox PTA, BLUE MAX, 
Powerflex P3) were used with a balloon diameter ranged from 4-6 $\mathrm{mm}$ in combination of hydrophilic wires of diameter $0.018-0.035$ inch . Balloon diameter was chosen according to vessel size. 5000 units heparin were given intraarterially before balloon inflation. Inflation devices were used to inflate the balloons. Inflation pressure was up to 8 atmospheres with inflation duration of 1 minute . Completion arteriography was performed in all cases using non ionic contrast medium (Ultravist). All patients received low molecular weight heparin $40 \mathrm{mg}$ subcutaneously 4-6 hours after the procedure and $150 \mathrm{mg}$ aspirin daily. Ankle/brachial pressure index (ABPI) and segmental limb pressure were measured the day after angioplasty to all patients and compared with the preprocedural value. Patients were observed in the hospital after the procedure. The puncture site was inspected before discharge.

The patients were evaluated at 1-, 6-, 12-, 18and 24 months periods. The ABPI was recorded at each visit. If clinically warranted, Duplex ultrasound was performed.

Criteria of success and failure :

Technical success is defined as restored patency of the vessel with an angiographic residual diameter stenosis of $<30 \%$ and a residual translesion pressure gradient $<10$ $\mathrm{mmHg}$.

Limb salvage after treatment of CLI is defined as the preservation of a functional limb, including at least part of the foot, without requirement for prosthesis.

Haemodynamic Success is defined as an increase in the ABPI of more than 0.10.

Patency was defined as maintainance of achieved homodynamic improvement in the relevant segment i.e. not more than 0.10 below the highest postoperative index. If a drop more than 0.10 is measured, proof of patency with vascular imaging is required.

Primary patency : a revascularised segment is considered to have"primary" patency if it has had uninterrupted patency with either no procedure performed on it or a procedure to deal with disease progression in the adjacent native vessel.

\section{Results:}

\section{Patient demographics:}

There were forty patients $(32$ men and 8 women) with median age 59 years

Twenty-four patients $(60 \%)$ had ischemic rest pain, $9(22.5 \%)$ had minor tissue loss, 7
(17.5\%) had major tissue loss. Femoropopliteal PTA procedures performed for claudication are excluded. Twenty-five patients $(62.5 \%)$ had diabetes, $20(50 \%)$ had ischemic heart disease (IHD), 28 (70\%) had hypertension, 15 (37.5\%) had dyslipidaemia, $30(75 \%)$ had history of smoking, and 4 (1\%) had cerebrovascular disease.

\section{Lesion criteria:}

Among 40 PTA procedures, 18 were of the SFA , 7 of the popliteal artery, 9 of both arteries and 6 for the CFA. Twenty-nine (72.5\%) procedure performed for stenotic lesions ( 19 for focal stenosis and 10 for multiple stenosis) and 11 for occlusions ( 7 for short occlusion $<5 \mathrm{~cm}$ and 4 for long occlusions $>5 \mathrm{~cm}$ ). Good run off (2-3 vessels) was the finding in 28 arteriogram and poor run off (0-1 vessel) in 12 arteriogram.

\section{Technical Success :}

The technical success rate was $95 \%$. Technical failure occurred in two patients, the first resulted from inability to cross occlusive lesion $>5 \mathrm{~cm}$ at the level of SFA, this patient was treated by elective femoropoplitel bypass grafting using synthetic PTFE graft after 10 days of intervention. The second resulted from residual stenosis $>30 \%$ after PTA of the SFA this patient was treated successfully by stenting

\section{Complications:}

Three cases were complicated by groin hematomas. The hematomas were so small that they not required transfusion. One case was complicated by arterial spasm treated with vasodilators and heparainization. One patient developed femoral neuralgia syndrome, the pain persisted for 6 weeks (Hallett et al., 1990). Infection did not record at the puncture site (Hampton and Sherertz .,1988).

\section{Hospital stay and mean follow up:}

Mean hospital stay was 5 days and mean follow up was 16 mo.

\section{Limb Salvage :}

Two major amputations were performed during the follow up period. The first was performed at 6 months and the second at 23 months after PTA.

\section{Patient Survival :}

The patient survival rate at two years of angioplasty was $95 \%$. Two patients $(5 \%)$ died within 12 months of angioplasty. One in the hospital after three days of operation, the cause of death was heart failure due to extensive myocardial infarction. The second patient was died after 12 months of angioplasty at home. 


\section{Patients Escaped Follow up :}

Two patients escaped follow up. One at 5 months and the other at 11 months. The two cases included in number of failed cases.

at $1,6,12$, and 24 months for stenoses were $93.1 \%, 86.2 \%, 75.9 \%$, and $75.9 \%$ respectively. Cumulative primary patency rates at $1,6,12$, and 24 months for occlusive lesions were $72.7 \%, 54.5 \%, 54.5 \%$, and $45.5 \%$ respectively. Primary patency rate at 24 months for short occlusions was $57.1 \%$ and for long occlusions was $25 \%$. Primary patency rate at 24 months for focal stenosis was $89.5 \%$ and for multiple stenosis was $50 \%$. Primary patency rate at 24 months for lesions with good run off and with bad run off were $75 \%$, and $50 \%$ respectively. Primary patency rates at 24 months for diabetic and non diabetic patients were $50 \%$, and $80 \%$ respectively. Primary patency rates at 24 months for smokers and non smokers were $45.4 \%$, and $78.9 \%$ respectively.

Patients underwent secondary interventions :

\section{Primary patency:}

Overall primary patency rates at $1,6,12$, and 24 months were $87.5 \%, 77.5 \%, 70 \%$, and 67.5 respectively. Cumulative primary patency rates

Three patients with SFA lesions were treated with secondary stenting after failure of PTA at the same time of PTA due to residual stenosis $>30 \%$, then at $5 \mathrm{mo}$, and 11 months respectively due to recurrent stenosis. Two patients with SFA lesions were treated successfully by elective femoropoplitel bypass grafting using synthetic PTFE graft, the first was done 10 days after technical failure of PTA and the second was done after one month of PTA. Two patients with popliteal artery lesions were secondary treated with femorotibial bypass using autogenous in situ, great saphenous vein graft, the 1 st after 1 mo of PTA, and the second after 4 months of PTA. Two patients were secondary treated with major amputation, the first after 6 months of PTA and the second after 23 months of PTA.

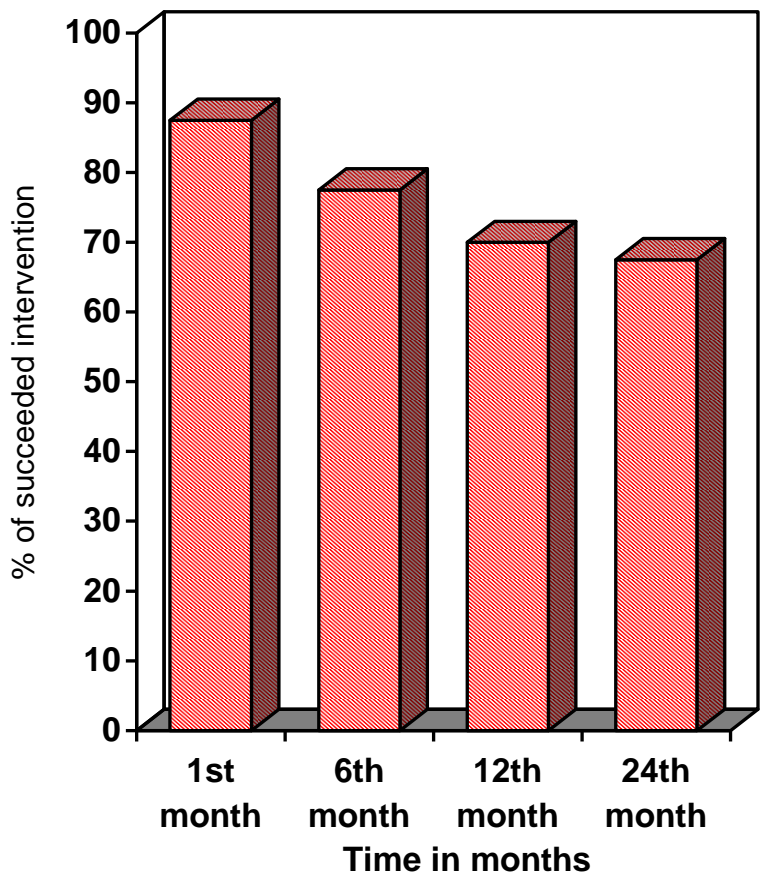

Fig (1):

Percentage of succeeded cases in relation to follow- up periods

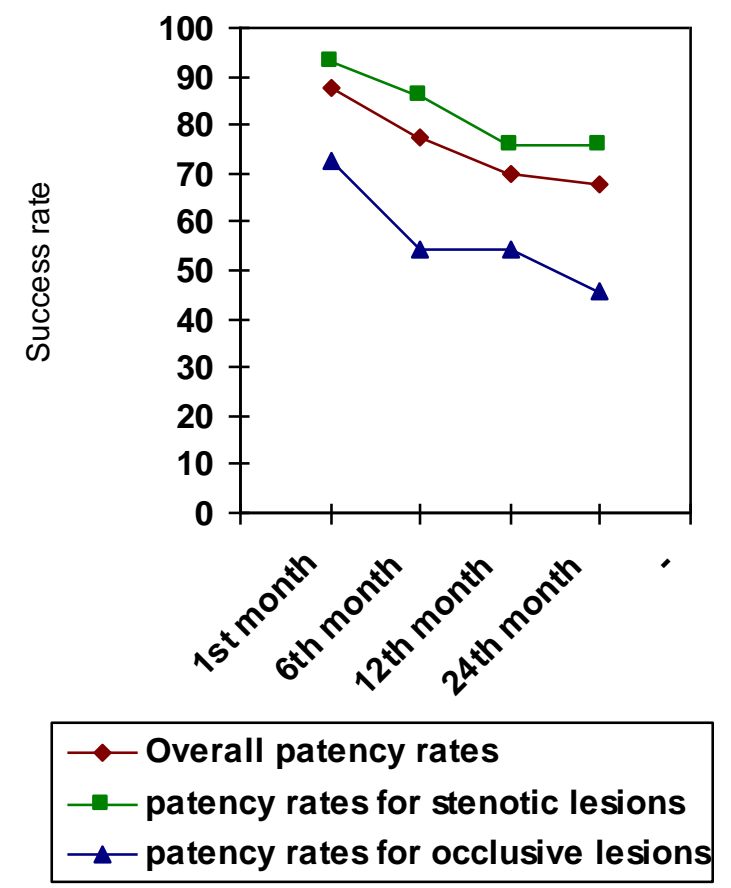

Fig (2):

Overall patency rates, patency rates for stenotic and occlusive lesions.

N.B. Technical failure and patients escaped follow up are included in the failed cases. 
A Study to Assess The ...

Fig. (3)
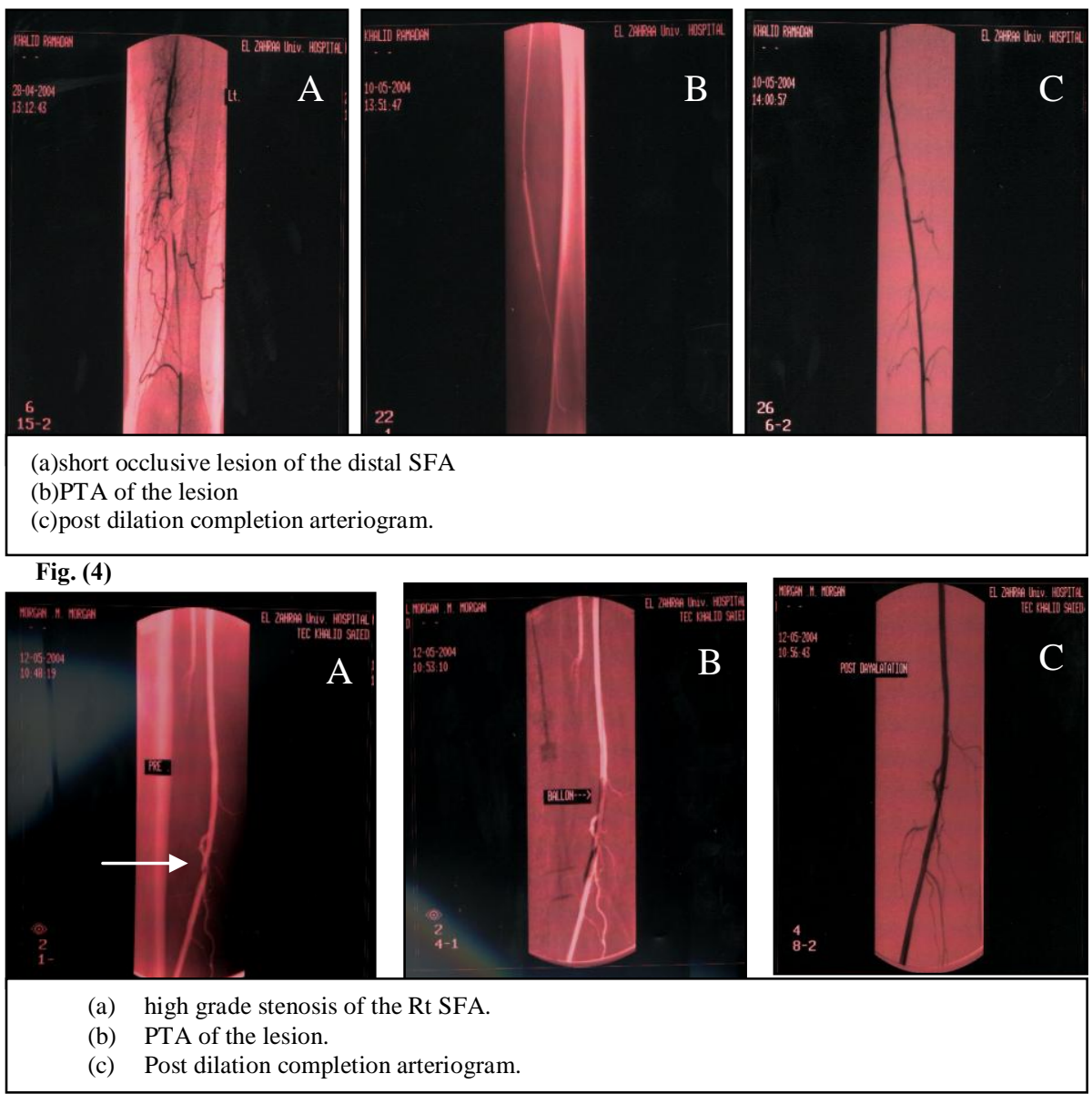

Fig. (5)

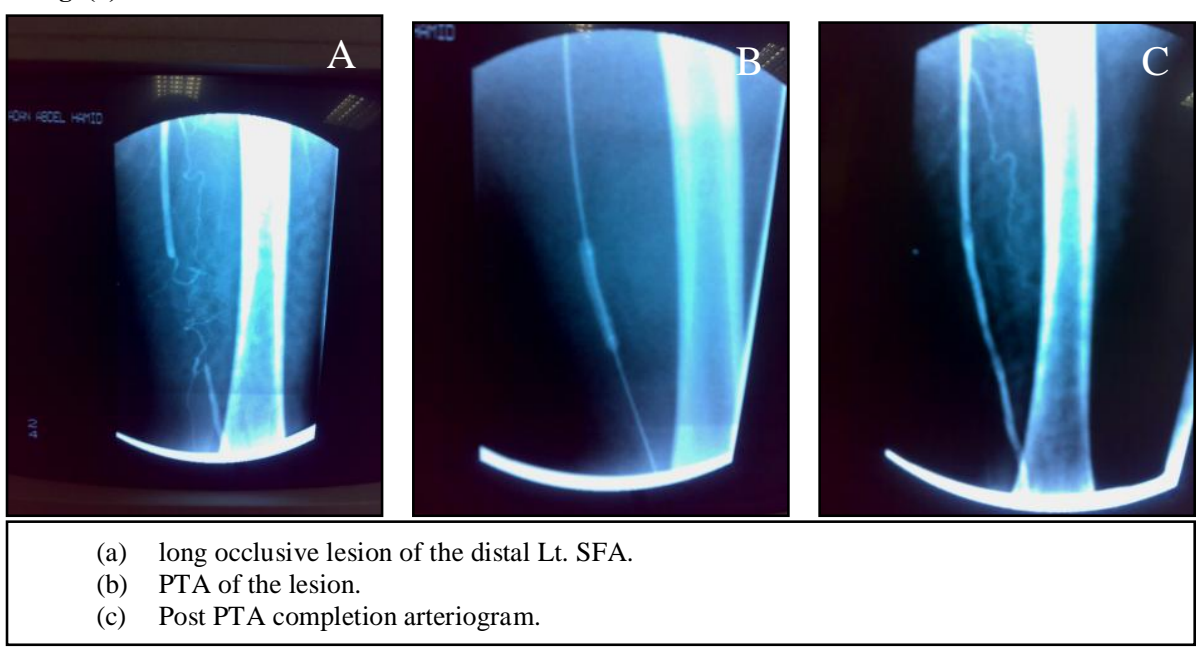




\section{Discussion:}

The overall primary patency rate at 24 months was $67.5 \%$, which is around the figures of several previous studies (London et al., 1995) .

The 2 years cumulative primary patency rate of femoropopliteal PTA seemed to be near the results of the infrainguinal bypass grafting reported in the literature of Dalman and Taylor (1998). Previous longterm studies reported the superiority of infrainguinal bypass grafting over PTA regarding the 5-year \% patency (TASC II, 2007b). Procedure related complications, limb salvage, patient survival are much better than bypass surgery. PTA did not preclude future bypass grafting (AnneMarie, 2001).

Factors predicting outcome of PTA were evaluated in this study and classified into:

- Lesion characteristics.

- Patient demographics.

- Initial hemodynamic response.

Lesion Characteristics :

Stenotic lesions showed better results than occlusive lesions (Capek et al., 1991). Short occlusions and focal stenotic lesions had better results than long occlusions and multiple stenotic lesions respectively. A previous study had shown the same results (Hunink et al., 1994).

Patients with good run off showed significant higher long term patency rates than patients with poor run off. A previous study had reported that patients with poor (0 - to 1 vessel) runoff consistently showed poorer long-term outcomes than those with 2-3 vessel run off (Johnston., 1992). Another study documented 2-year patency rates after femoropopliteal PTA as 55\% in limbs with good run off and $23 \%$ in limbs with poor run off (Stanley et al., 1996).

\section{Patient Demographics:}

Diabetic patients were doing worse than non diabetics after a year, though 1-month results were not significantly different (Danielsson et al., 2001). Smokers and hypertensive patients has a significantly worse outcome (Sayers et al., 1994).

Initial Hemodynamic Response :
After angioplasty, the extent of improvement in the ankle brachial pressure index (ABPI) serves as an indicator of the immediate hemodynamic improvement and also as a prognostic indicator. The mean ABPI after PTA was 0.6. Previous study showed that, improvement in the ABPI after PTA has been shown to be strongly predictive of sustained patency (Kumpe and Jones., 1982).

So, factors predictive for a favorable outcome are short lesions, stenoses, good distal run off, non diabetics, non hypertensive, and non smokers.

\section{Conclusion:}

Because of:

1- Femoropopliteal PTA performed for treatment of CLI achieved an overall 2 years primary patency rate that is near the results of infrainguinal bypass grafting reported in literature

2- PTA does not contraindicate the performance of future bypass surgery .

3- PTA has low morbidity and mortality.

4- PTA performed under local anaesthesia .

5- PTA avoids the hemodynamic instability associated with clamping and declamping that further add to the patient's risk.

6- PTA does not need postoperative admission in intensive care unit.

7- PTA is combined with short term hospital admission.

So, PTA is considered a first choice and an accepted alternative to bypass surgery in patients with femoropopliteal stenotic and short occlusive lesions who presented with CLI.

\section{References:}

1. Anne-Marie (2001): percutaneous transluminal angioplasty of the femoropopliteal arteries in limbs with chronic critical lower limb ischemia: J. Vasc . Surg ., 34: 114-121

2. Capek P,Melean GK and,Berkowitz HD (1991) ; Femoropopliteal angioplasty factors influencing long term success. Circulation; 83(1) : 70-80.

3. Dalman RL and Taylor LM (1998): Basic data related to infrainguinal revascularization procedures. Ann. Vasc. Surg., 4: 319-322

4. Danielsson G, Albrechtsson $U$, Norgren $L$ et al. (2001) : Percutaneous transluminal angioplasty of Crural arteries : Diabetes and 
other factors influencing outcome. Eur. J. Vasc. Endovasc. Surg., 21:432-436.

5. Hallett JW, Wolk SW,Cherry KJ et al. (1990) : The femoral neuralgia syndrome after arterial catheter trauma. J. Vasc. Surg., 11:702706.

6. Hampton AA and Sherertz RJ (1988): Vascular access infections in hospitalized patients. Surg. Clinic. North. Am., 68:57-71.

7. Hunink MGM, Donaldson MC, Meyerovitz MF et al. (1994) : Risks and benefits of femoropopliteal percutaneous balloon angioplasty. J. Vasc. Surg., 17:183-194. 8. Johnston, K.W. (1992): Femoral and popliteal arteries: Reanalysis of results of balloon angioplasty. Radiology, 183:767-771.

9. Kumpe DA and Jones DN (1982): Percutaneous transluminal angioplasty: Radiological view point. Vasc. Diagn. Ther., 3:19-21.

10. London NJM, Varty K, Sayers RD et al. (1995): Percutaneous transluminal angioplasty for lower limb critical ischemia. Br. J. of Sur., 82:1232-1235.

11. Nasr MK, Mc Carthy RJ, Hardman J, Chalmers $A$ and Horrocks $M$ (2002): The increasing role of percutaneous transluminal angioplasty in the primary management of critical limb ischemia. Eur. J. Vasc. Endovasc. Surg., 23:398-403.

12. Sayers RD,Thompson MM, Hartshorne T et al. (1994) : Treatment and outcome of severe lower limb ischemia. Br. J. Surg., 81:521-523. 13. Stanley, B.; Teague, B.; Raptis, S. et al. (1996) : Efficacy of balloon angioplasty of the superficial femoral artery and the popliteal artery in the relief of leg ischemia. J. Vasc. Surg., 23:679-685.

14. TASC II (2007a): Infrainguinal revascularization. J. Vasc. Surg., 45 (1), Pp: S52.

15. TASC II Recommendation 16 (2007) : clinical definition of CLI : J. Vasc. Surg., 45(1) Pp: S29A. 
دراسة لتقييم نتائج عمليات توسيع الثرايين الفخذية والمأبضية باستخدام بالونات التوسيع فى المرضى المصابين بقصور مزمن حرج بالدورة الاموية للطرية بالينين السفليين

$$
\begin{aligned}
& \text { إيهاب محمد عبده-حاتم أحمد مجاهد-عبد العزيز أبو العلا } \\
& \text { كلية الطب -جامعة الأز هر الهم }
\end{aligned}
$$

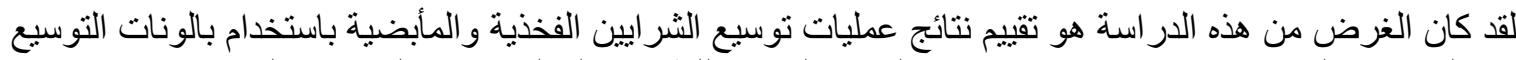

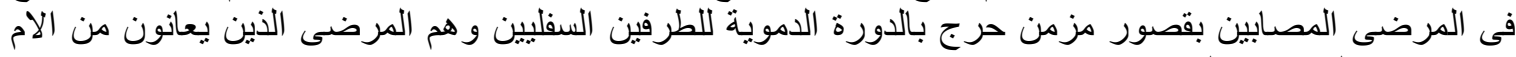

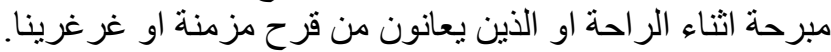

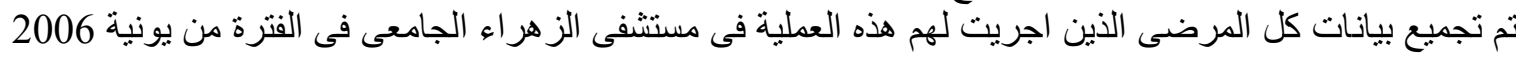
الى مايو 2008 وتم در اسة هذه النتائج احصائيا.

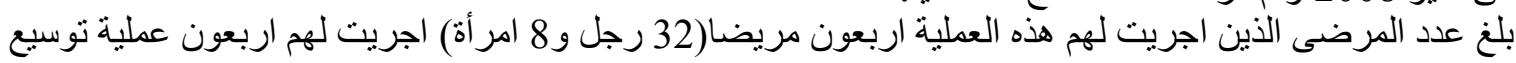

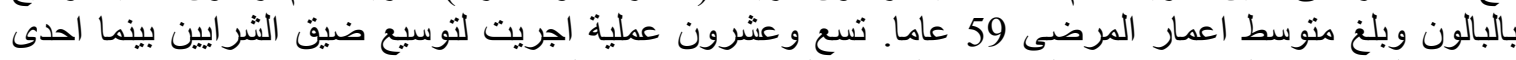

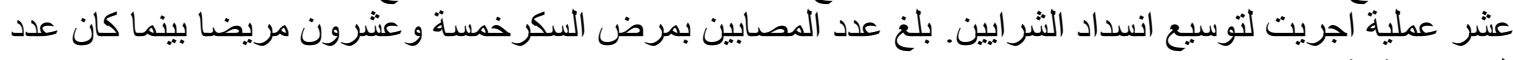

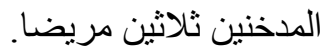
بلغت نسبة نجاح هذه التقنية في وقت التهات العملية سبع وتسعون ونصف بالمائة. وبعد دراسة النتائج المترتبة على هذه

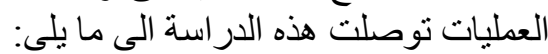

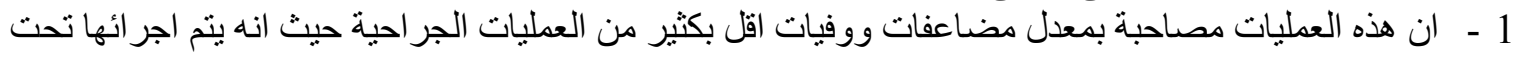
مخدر موضعى. 2 - ان معدل نجاح هذه العملية بعد 24 شهر ا من المتابعة يقترب كثير ا من معدل نجاح العمليات الجر احية.

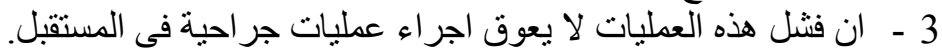

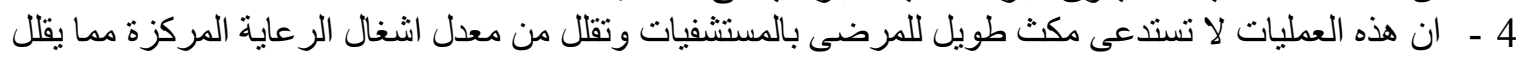
من تكاليف العلاج. 5 - أن هناك عو امل ثقلل من معدلات نجاح هذه العمليات مثل الاصابة بمرض السكر والتنخين والانسداد الطويل

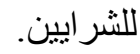

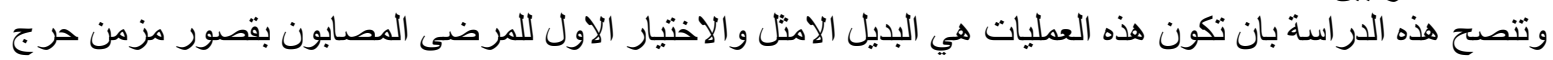

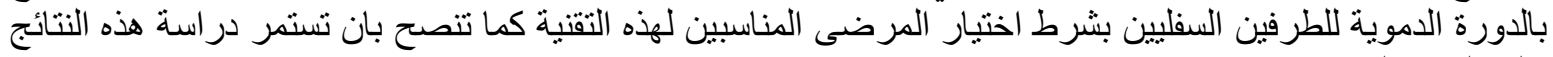

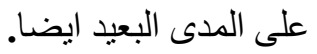

